\title{
Understanding SGML and XML Tools
}

Practical programs for handling structured text 


\section{RELATED PUBLICATIONS}

THE SGML FAQ BOOK: Understanding the Foundation of HTML and XML Steven J. DeRose ISBN: 0-7923-9943-9

INFORMATION RETRIEVAL AND HYPERTEXT, Maristella Agosti, Alan Smeaton, editors ISBN: 0-7923-9710-X

HTML AND THE ART OF AUTHORING FOR WORLD WIDE WEB, Bebo White ISBN: 0-7923-9691-X

RETHINKING HYPERMEDIA: The Microcosm Approach, Wendy Hall, Hugh Davis, Gerard Hutchings ISBN: 0-7923-9679-0

MAKING HYPERMEDIA WORK: A User's Guide to HyTime, Steven J. DeRose, David G. Durand ISBN: 0-7923-9432-1

PRACTICAL SGML, Second Edition, Eric van Herwijnen ISBN: 0-7923-9434-8

PRACTICAL SGML, Eric van Herwijnen ISBN: 0-7923-0635-X 


\title{
Understanding SGML and XML Tools
}

\author{
Practical programs for \\ handling structured text
}

by

Peter Flynn

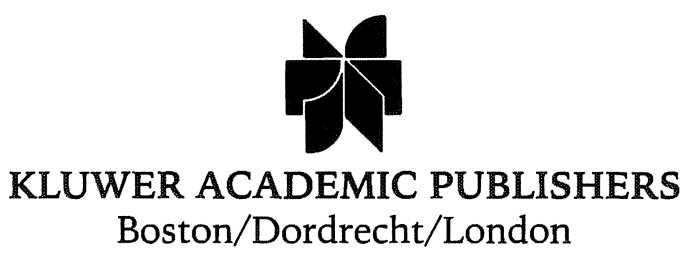


Distributors for North America:

Kluwer Academic Publishers

101 Philip Drive

Assinippi Park

Norwell Massachusetts 02061 USA

Distributors for all other countries:

Kluwer Academic Publishers Group

Distribution Centre

Post Office Box 322

3300 AH Dordrecht, THE NETHERLANDS

\section{Library of Congress Cataloging-in-Publication Data}

A C.I.P. Catalogue record for this book is available from the Library of Congress.

ISBN-13: 978-1-4684-6713-0 e-ISBN-13: 978-1-4684-6711-6

DOI: $10.1007 / 978-1-4684-6711-6$

Copyright $(\subset) 1998$ by Kluwer Academic Publishers

Softcover reprint of the hardcover 1st edition 1998

All rights reserved. No part of this publication may be reproduced, stored in a retrieval system or transmitted in any form or by any means, mechanical, photocopying, recording, or otherwise, without the prior written permission of the publisher, Kluwer Academic Publishers, 101 Philip Drive, Assinippi Park, Norwell, Massachusets 02061

Printed on acid-free paper. 
For Teresina 


\section{Table of Contents}

How to use this book $\ldots \ldots \ldots$ niii

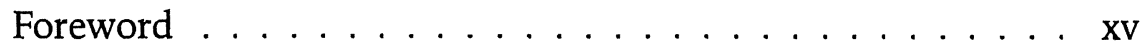

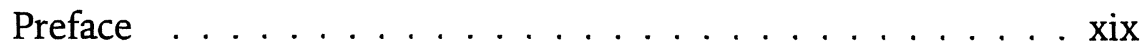

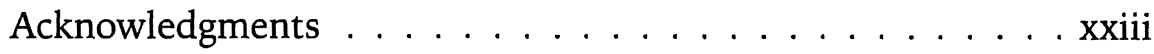

Technical notes . . . . . . . . . . . . . . . xxv

1 Introduction 1

1.1 What it's all about . . . . . . . . . . . . 1

1.2 Selection of tools . . . . . . . . . . . . . . . 3

1.3 How much do I need to know about computers? . . . . . 4

1.3.1 Essential: basic computing . . . . . . . . . 5

1.3.2 Important: textual skills . . . . . . . . . . . . 6

1.3.3 Nice-to-have: basic networking . . . . . . . . . 6

1.4 Organization of the book . . . . . . . . . . 7

1.5 The quick-start guide to SGML . . . . . . . . . . 8

1.5.1 So what is markup and what is SGML? . . . . . . 9

1.5.2 Why you should consider SGML or XML . . . . 32

1.5.3 Dispelling some of the myths about SGML . . . 33

1.5.4 Where to get more information . . . . . . . . 39

2 What type of document? 43

2.1 Describing the type of document . . . . . . . . . . 44

2.1.1 The DocType Declaration Internal Subset . . . . . 47

2.2 Understanding Document Type Definitions . . . . . . . . 49

2.2.1 Terms and techniques in DTD construction . . . . 56

2.3 What's available in public? . . . . . . . . . . 66

2.3.1 DTDs for office documents . . . . . . . . 66

2.3 .2 Industrial DTDs . . . . . . . . . . . 76

2.3.3 DTDs for technical writing and documentation . . 79 
2.3.4 DTDs for general publishing . . . . . . . . 84

2.3.5 DTDs for military use . . . . . . . . . . . 89

2.3.6 DTDs for research and academic use . . . . . . 92

2.3.7 DTDs for Tables . . . . . . . . . . . . . . . 104

2.3.8 DTDs for mathematics . . . . . . . . . . 111

2.3.9 DTDs for the Web . . . . . . . . . . . . . 122

2.4 Extensible Markup Language (XML) . . . . . . . . . 132

2.4 .1 XML syntax . . . . . . . . . . . . . . . . 133

2.4 .2 XML Links . . . . . . . . . . . . . . . . 140

2.4 .3 XML Stylesheets . . . . . . . . . . . . . . . . . 143

2.4 .4 XML Data . . . . . . . . . . . . . . . . . . 144

2.5 Identifying the DTD . . . . . . . . . . . . . . . 145

2.5.1 System Identifiers . . . . . . . . . . . . . 145

2.5.2 Formal Public Identifiers . . . . . . . . . . . . 146

2.5.3 Locating the DTD and other entities . . . . . . . 150

2.5.4 The OASIS catalog (SGML Open catalog) . . . . . 153

2.6 Writing and modifying DTDs . . . . . . . . . . . 160

2.6.1 Modifying a DTD . . . . . . . . . . . . . . 163

2.6.2 NearEFar Designer (Microstar) . . . . . . . . . . 172

2.6.3 Graphical DTD Viewer (Corel) . . . . . . . . . . . 177

2.6.4 EasyDTD (Norm Smith) . . . . . . . . . . . . . . 178

2.6 .5 ezDTD (Duncan Chen) . . . . . . . . . . . . . 180

2.6.6 NormDTD (Richard Light) . . . . . . . . . . . 181

2.6 .7 SP (James Clark) . . . . . . . . . . . . . . . . . 182

2.6.8 Carthage (Michael Sperberg-McQueen) . . . . . 184

2.6 .9 Fred (OCLC) . . . . . . . . . . . . . . . . . 184

2.7 SGML update . . . . . . . . . . . . . . . . . . 187

2.7.1 The SGML Standard . . . . . . . . . . . . . . 188

2.7.2 Associated standards . . . . . . . . . . . . 193

3 Editors 201

3.1 Editors and DTDs . . . . . . . . . . . . . . 202

3.1.1 Resources needed for compilation . . . . . . . . 203

3.1.2 What to do with compiled DTD files . . . . . . . . 207

3.2 Stylesheets and WYSIWYG . . . . . . . . . . . . . 208

3.3 General-purpose editors . . . . . . . . . . . . . . 212

3.3.1 ADEPT•Editor (ArborText) . . . . . . . . . . 213

3.3.2 Author/Editor (SoftQuad) . . . . . . . . . . . 219

3.3.3 SGML Editor (GriF) . . . . . . . . . . . . . . . 224

3.3.4 Document Generator and WebWriter XML (Stilo) . . 228

3.3.5 InContext 2 (InContext) . . . . . . . . . . . 231

3.3.6 XED Henry Thompson . . . . . . . . . . . . . . 234 
3.4 SGML extensions to non-SGML editors . . . . . . . . 235

3.4.1 GNU Emacs and psgml-mode . . . . . . . . . . 236

3.4.2 WordPerfect Suite 8 (Corel) . . . . . . . . . . . . 239

3.4.3 NearEFar Author for Word (Microstar) . . . . . . 244

3.4 .4 SGML Tagger (OUP) . . . . . . . . . . . . . . 246

3.4.5 The MultiDoc Translating Editor (Citec) . . . . . 249

3.4 .6 The Euromath editor . . . . . . . . . . 250

4 Parsing and validating 253

4.1 Using a built-in parser . . . . . . . . . . . . . . 255

4.2 Interpreting and reusing parser output . . . . . . . 257

4.2.1 Understanding parser errors . . . . . . . . . 257

4.2.2 ESIS (Element Structure Information Set) . . . . . 263

4.3 Stand-alone parsing . . . . . . . . . . . 266

4.3.1 ARC-SGML (Charles Goldfarb) . . . . . . . . 267

4.3.2 ASP (Jos Warmer) . . . . . . . . . . . 267

4.3.3 Mark-It! (SEMA Group) . . . . . . . . . . . . 267

4.3 .4 sgmls (James Clark) . . . . . . . . . . . . 268

4.3 .5 SP and nsgmls . . . . . . . . . . . . 271

4.3 .6 SMPOO (YASP) . . . . . . . . . . . . 273

4.3 .7 XML parsers . . . . . . . . . . . . . 273

5 Manipulation and conversion $\quad 281$

5.1 Quick and dirty: using non-SGML tools . . . . . . . 282

5.1 .1 Unix utilities . . . . . . . . . . . . . . 283

5.1 .2 sgrep (University of Helsinki) . . . . . . . . . . 297

$5.1 .3 \mathrm{Perl}$ (Larry Wall) . . . . . . . . . . . . . . 298

5.1 .4 Python . . . . . . . . . . . . . . . 304

5.2 Programmable conversion engines . . . . . . . . 304

5.2.1 Omnimark (Omnimark) . . . . . . . . . . . 305

5.2.2 SGMLC (SGML Systems Engineering) . . . . . . 310

5.2.3 Balise (AIS Berger-Levrault) . . . . . . . . . . 313

5.2 .4 Jade (James Clark) . . . . . . . . . . . . . . 317

5.3 SGML export and import without programming . . . . 319

5.3.1 RainbowMaker (Inso) . . . . . . . . . . . . . 320

5.3.2 Dynatag (Inso) . . . . . . . . . . . . . . . . . . . . . . . . . . . . . .

5.3.3 SGML Author for Word (Microsoft) . . . . . . . . 327

5.3 .4 Roustabout (Apropos) . . . . . . . . . . . . 331

5.3.5 TagPerfect (Delta Computers) . . . . . . . . . . 332

5.3.6 ACS (Lockheed-Martin) . . . . . . . . . . . . . 334

5.3.7 SGML-Tools (LinuxDoc) . . . . . . . . . . . 335 
6 Finding, viewing, and printing 339

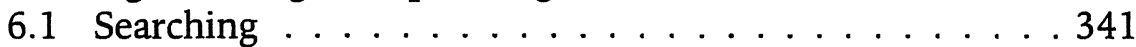

6.2 Viewers and browsers . . . . . . . . . . . . . 343

6.2 .1 DynaText (Inso) . . . . . . . . . . . . . . . . 344

6.2 .2 ViewPort (Inso) . . . . . . . . . . . . . . . 348

6.2 .3 Panorama (SoftQuad) . . . . . . . . . . . . . 352

6.2.4 MultiDoc Pro (Citec) . . . . . . . . . . . . . . . 354

6.2.5 Babble (University of Virginia) . . . . . . . . . 356

6.2 .6 Sara (OTA) . . . . . . . . . . . . . 357

6.3 Non-visual representations . . . . . . . . . . . . . . 359

6.4 Stylesheet software . . . . . . . . . . . . . . . . 360

6.4.1 The XML Styler (ArborText) . . . . . . . . . . 361

6.5 Printing and publishing . . . . . . . . . . . 362

6.5 .1 Into print fast . . . . . . . . . . . . 362

6.5.2 Publishing and typesetting systems . . . . . 363

6.5.3 Programmable batch systems . . . . . . . . . . . 369

6.6 Document management and archiving . . . . . . . . 369

6.6 .1 Database systems . . . . . . . . . . . . 370

7 Rolling your own 377

7.1 Toolkits for the programmer . . . . . . . . . 378

7.1 .1 YASP . . . . . . . . . . . . . . 378

7.1.2 LT NSL (Language Technology Group) . . . . . . . 379

7.1.3 LT XML (Language Technology Group) . . . . . . . 380

7.1.4 S4-Desktop (I4I) . . . . . . . . . . . . . . . 381

A The CD-ROM 383

A.1 Browsing the CD-ROM: using Synex/Inso ViewPort . . . . 384

A.2 Words of warning about the software . . . . . . . . 384

A.3 How does it work? . . . . . . . . . . . . . . . . . 384

A.4 What am I allowed to do with it? . . . . . . . . . . 388

A.5 Documentation . . . . . . . . . . . . . . . . 388

A.6 GNU software . . . . . . . . . . . . . . . . 389

B SGML resources 391

B.1 On the Web . . . . . . . . . . . . . . . 391

B.2 Usenet news . . . . . . . . . . . . . . . . . 391

B.3 Mailing lists . . . . . . . . . . . . . . . . . . . . . 392

B.4 SGML User Groups . . . . . . . . . . . . . . . . 394

References . . . . . . . . . . . . . . . 399

Glossary . . . . . . . . . . . . . . . . . . . 401

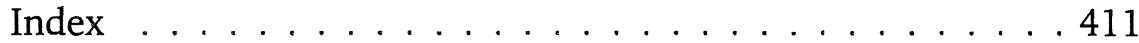


Index of people and organizations . . . . . . . . 423

Index of markup elements and parameters . . . . . . . 425

Index of acronyms and abbreviations . . . . . . . . . 431 


\section{How to use this book}

If you've used SGML before, or if you haven't but you're in a hurry:

- Section 1.4 has a short list and explanation of the chapters.

- Each chapter has a mini table of contents at the start, so you can see what it covers.

Otherwise if you're just starting with SGML, read chapter 1 first, and use the software on the CD-ROM to get a feel for how it works and what you can do.

I use a few standard typographical and indexing conventions:

- markup and other examples of computer text are in fixed-width type: element names, attribute names, and other SGML parameters are indexed separately starting on page 425 ;

- I use bold italics the first time a new term is introduced: it is summarized in the Glossary starting on page 401 and it gets a page number in bold in the Index so you can find it again;

- company and program author names are indexed separately starting on page 423 . 


\section{Foreword}

Peter Flynn has been an enthusiastic and skillful contributor in the world of SGML and XML for many years, and it is a pleasure to see him set some of his expertise down in writing as well. The range and power of SGML tools have taken a sharp upward turn: the first step leading to this was that the Web came along with HTML, and showed the whole world that pointy brackets and (at least somewhat) descriptive markup could make a difference. Soon afterward, 'HTML claustrophobia' began to grow and XML came to the rescue. Since XML is fundamentally an elegant subset of SGML that reduces complexity without reducing functionality, the movement to XML is great for SGML too.

The massive interest in XML is bringing forth a huge variety of new, faster, more powerful, and cheaper software tools. Peter has caught the cusp of this change and shows in detail how SGML and XML tools fit together into integrated solutions that return value for your investment in structured information.

SGML long ago became the normative way of doing serious documents in mission-critical and large-scale publishing; my own work has largely been in developing SGML delivery systems used in the aerospace, power, telecommunications, hardware and software industries, where technical manuals often outweigh the aircraft or other devices they document. SGML was the only practical choice for such information, and software that could handle huge SGML documents 
safely, reliably, and rapidly improved productivity and costs often by many millions of dollars per company per year.

SGML also caught on in a second arena under quite different circumstances: scholarly texts. Although no one is likely to die if an SGML system fails on complicated markup for manuscripts variation or multilingual synchronization, such texts often stress tools even further in terms of features and performance than most high-end publishing applications. As Michael Sperberg-McQueen noted in the closing keynote of SGML/XML '97, scholars are the 'canaries in the mineshaft' of the SGML community. They are far more sensitive to problems (such as poor DTD design, unscalable software, etc) and therefore tend to keel over sooner, signaling those in the industry of problems. And just as in the depths of a coal mine, those less sensitive are well advised to notice and fix the problem, lest it get to them soon after.

SGML moved beyond these two areas only slowly, however, until the Web. Now everyone is experiencing different markup systems firsthand. They go to beautiful pages with carefully adjusted layouts, then come back with a different browser version or a different window size, and fail. Or they go to sites that adjust automatically, using their builtin knowledge of structure in their information resources to customize display for exactly the user's circumstances and preferences. Web managers with the first sort of site are watching their costs skyrocket, and are (sometimes desperately) seeking tools to manage rapidly growing complexity. In short, the power of descriptive markup is now a perceived need.

This new popularity also makes for a large and diverse tool environment, and it is there that Peter's book is perhaps most valuable. He provides a guide to the labyrinth of SGML and XML tools, organized carefully in the way many users need it: in terms of the life-cycle of their documents. Rather than going into every detail of each system, or providing a user's guide that would be wholly outdated almost before reaching the shelves, he presents various systems' distinctives: what is it that stands out in product $\mathrm{X}$, and why might I use it? These distinctives often reflect the fundamental approach of each system, which is much more stable than the feature details of a given release. The focus here is on seeing the SGML and XML tool landscape, rather than individual trees (or as in a few books, the veins in the leaves!). This approach promises great practical advantages in helping the reader actually evaluate tools and make wise choices in the face of ever-growing diversity.

Such a book could easily be dry, but the reader will quickly realize that this book comes out of real experience with the tools. The many 
anecdotes and witty summaries make it much more accessible. The survey of DTDs reflects this as well: few authors could speak competently about the enormous range of DTDs covered here, or do so with a sense of history. Anyone considering work with SGML or XML will find this book very useful indeed. 


\section{Preface}

In Charles Manby Smith's A Working Man's Way in the World[37] there is an example quoted of a 19th century printer's proofreader at work, with his reading-boy sitting beside him reading the copy aloud while the proofreader checks it:

'This ruling passion two ital par the most enduring of all the passions which obtains a mastery over the mind close is described in Pope's eps thus turns odious in woollen 'twould a saint provoke close were the last words that poor narcissa spoke turns no let a charming chintz and Brussels lace wrap my cold limbs and shade my lifeless face one need not sure be frightful though one's dead and Betty.' [...]'Give my cheek a little red close turns again I give and devise close old Euclid said and sighed turns my lands and tenements to Ned close turns again your money sir close turns again my money sir what all why if I must close then wept turns again I give it Paul close he cried turns again not that I cannot part with that close and he died pop ep one oct ed $p$ two five three.'

Smith clearly picked this particular example because it was popular in 1846 (he notes that 'everybody knows the above passage', although I have been unable to trace it), but the point he was making was that to achieve correct printing, the text had to be interlarded with technical terms (distinguished in the quotation) when it was spoken to a proofreader. Any errors would be marked up on the printed proof, and 
returned for correction to the compositor who set the type. Although proof-correction markup is not quite the same thing as SGML markup, the intention is similar: to indicate the meaning behind the text. Emphasis, quotation, and poetic linebreaks can all be seen in the example above.

In this sense electronic texts are no different from paper ones: they also need markup, and the conventional way of applying this in a word processor or desktop publishing system is to press the buttons or use the mouse until the text 'looks right'. The difference between paper and electronic texts, however, is that computers cannot generally detect the significance of a word just by its position and appearance, as humans can. Putting these words into italics, for example, has no actual meaning unless you know what the italics signify, and this often depends on the context. Italics could mean emphasis, a product name, a scientific name, a foreign word, a program variable, a list sub-heading, or just sloping letters because they look nice.

Just making things look right is fine if the sole destination is print, and the text is guaranteed never, ever to be wanted for any other purpose. For text which is to be handled by a computer for any other reason, and especially for reprocessing for a variety of other outputs, it needs clear and unambiguous markup that can be read by different programs on different computers, but following the same series of welldefined steps. SGML provides a language for defining exactly this kind of markup, and this book is all about how to make it work and some of the programs you can use with it.

If you are actually doing the writing yourself - whether you are using SGML for business reports, space station manuals, legal records, a thesis, or your latest novel - you are probably more interested in what you are writing (the words, the meanings, the thoughts) than in its final appearance. This is normally at least true while you are occupied in the process of writing, because you may in fact not yet know what the final formatting is going to look like, and you may not have any control over it, either.

There certainly have been authors who spent their lives looking over the compositor's shoulder to make sure the typesetting was done exactly to their specification, but with a few exceptions their works have sunk below the horizon now. Everyone wants their work to 'look right', of course, but an author who spends more time fiddling with fonts and layouts than in doing the writing is unlikely to be very productive as a writer.

And nowadays, especially, that we have more media than just print to handle, we need a new paradigm, and a new set of tools to help 
us cope with them. This book is designed to guide you through the different types of tool you can expect to see. 


\section{Acknowledgments}

Dozens of people have helped in the making of this book, from the users whose comments on a mailing list or at a meeting made me ask questions, to the regular denizens of the comp.text.sgml newsgroup who have put up with my own questions for so long. Many of them distinguished themselves by answering my queries in great detail, unfortunately far too many to list them individually here, so I thank them now as a group for taking so much of their time to ensure I represented the facts correctly: if I have got it wrong anywhere, the blame is mine alone.

A special thank-you goes to all the software vendors who lent me review copies, sometimes including unpublished manuals and beta releases at short notice; and to the authors of public domain software and shareware for their unstinting generosity, both to me and to the SGML community at large. I would also like to express my gratitude to those who lent me equipment, time on their machines, software, manuals, and training material, as without them a substantial chunk of the book would have remained unwritten.

I want to thank my reviewers, Elaine Brennan, Martin Bryan, Steve DeRose, Betty Harvey, Eve Maler, James Mason, Liam Quin, and Wayne Wohler. Their suggestions were invaluable, and kept me from publicly putting my foot in my mouth quite spectacularly on at least five occasions (perhaps I should release the out-takes like film studios do!). 
Some smaller sections of the text were also reviewed by an assortment of students, colleagues, and friends, and them I thank also.

Two people, however, deserve not just my own thanks but that of almost every SGML user who has ventured onto the Internet in search of answers: Robin Cover for maintaining the SGML Web pages, and Steve Pepper, whose invaluable Whirlwind Guide to SGML Tools [34] remains the canonical online listing.

Most importantly to my wife Teresina goes my love and thanks for having put up with precarious stacks of software and manuals, and with my virtual absence while I blunted my fingers on the keyboard each evening. And to my children Rachael, Thomas, and Olivia I say thank you too for being so patient, and I promise we'll go places again now.

A final word of thanks must go posthumously to Yuri Rubinsky, for his encouraging words about the idea for this book while it was still only an idea, and only a couple of weeks before his untimely death. Along with many others I posted my own tribute to his memory, but I reproduce here his words that I quoted then, because as I write, what he said is on the verge of becoming reality. I had spoken with him at the end of 1992 about the Web and HTML: he was full of enthusiasm and said, 'Just think of it, in a few years the whole world could be using SGML.' It has taken a little over five years for the use of HTML-as-RTF to turn into SGML-as-XML, but it is possible that we are now passing a critical point of inflection on the adoption curve of SGML, and that the whole world will indeed be taking a much keener interest in how it works and what it can do for everyone. If this book helps you to move up that curve, then it has all been worthwhile. 


\section{Technical notes}

When I was finishing The World Wide Web Handbook[19], I was asked to include a note on what I had used to write it. At the time, HTML3 was still under discussion, and I said that I thought it unlikely that HTML in any form could be meaningfully used for a book. I still hold to this, although given enough semantic loading of attributes, it would probably just about be possible.

This book, like the previous one, was done using the Davenpor: Group's DocBook DTD, which is markup designed for computer manuals, the closest there is to computer books. I made a few very small changes to enable the use of tables and to add a few attributes to make life easier: these are documented in section 2.6.1.2. I used a variety of editors to do the actual writing, because it was all in SGML, which meant I could copy the text from platform to platform and back again according to where I was working and the kind of software I was looking at, allowing me to have the text open beside me all the time. The principal systems I used for the bulk of the writing were SoftQuad's Author/Editor and GNU Emacs.

Screenshots were mostly taken using JASC, Inc's Paint Shop Pro (PSP) v4.12 and Bruce Schuchardt's xgrabsc, saved as TIFF or XWD files and converted to PostScript with Jef Poskanzer's PBM or John Bradley's $x v$ for printing. Despite its ubiquity, TIFF can be a pain in the neck, as every manufacturer has invented their own little proprietary extensions for 
it, which are often stored in the file in weird ways. PSP is a great utility, but conversion to PostScript is not quite as good as in PBM, which in turn is not quite as robust as in $x v$.

For printed proofs, I used Panorama Publisher and MultiDoc Pro, both of which performed well. For the final output I experimented with several systems but fell back upon $\mathrm{BT}_{\mathrm{E}} \mathrm{X}$ partly because I know it better than anything else, and because it is very stable and reliable, dimensionally accurate, exhaustively documented, heavily supported, highly extensible and programmable, and runs on almost anything. The conversion of the DocBook SGML to $\mathrm{BT}_{\mathrm{E}} \mathrm{X}$ was done with Omnimark LE. 